\title{
Preschoolers' views on integration of digital technologies
}

\author{
Ora Segal-Drori ${ }^{1}$, Anat Ben Shabat ${ }^{2}$
}

\begin{abstract}
The aim of the present study was to explore preschool children's views on the integration of digital technologies in their school. The study included 171 Israeli children aged 3 to 6 who participated in in-depth interviews regarding their views on digital technologies in their preschool. The interviews were analyzed using content analysis. Three major views regarding digital technologies in the preschool were found: The degree to which digital technologies are necessary; the goals of the use of these technologies; the setting for using the digital technologies. Fifty percent of the children, especially the younger ones, claimed that use of these technologies is not necessary in preschool. However, most of them understood the importance of using these technologies and their contribution to many fields. In relation to the setting use, they referred to time and social aspects. The findings indicate that preschool teachers need to mediate these aspects more wisely and adapt them to the children's understanding and view toward digital technologies than actually takes place when they use them with the children.
\end{abstract}

\section{Article History}

Received: 09 November 2020

Accepted: 25 December 2020

\section{Keywords}

Children's views; Digital

technologies; Preschool

\section{Introduction}

Digital technologies, such as computers, tablets, smartphones, and others, have become an integral part of our lives and their influence is apparent in all life domains. Use of digital technologies has become increasingly common among children, both at home and in education settings, including schools and preschools (Holloway, Green, \& Livingstone, 2013; Ng, 2016). Studies in the world indicate increasing use of these technologies, already from early childhood (Elias and Sulkin, 2017; Kabali et al., 2015; Palaiologou, 2016a). Teachers and educators have concerns regarding the use of digital technologies by young children. One of the main arguments for not enabling children's exposure to digital technologies refers to children's passivity in these situations. The idea is that lack of physical and mental activity when watching the screen may inhibit development in many fields (Ebbeck, Yim, Chan, \& Goh, 2016). Concerns that increased use of screens will cause attention and focusing problems, cognitive decline and emotional and social problems were also raised (Ebbeck et al., 2016). However, these concerns have not been proven scientifically, and there is ambiguity surrounding this issue. The scientific literature is divided on this matter. On the one hand, there is evidence of a relationship (but not a proven causal relation) between extensive use of media means and attention problems, low achievements, and obesity (Brown, 2011; Chassiakos, Radesky, Christakis, Moreno, \& Cross, 2016). On the other hand, there is increasing evidence that well-designed digital technologies are effective in supporting children's development. Use of digital technologies was found to contribute to improvements in children's cognitive functions, such as memory, visual thinking skills, analogical thinking, abstract thinking, logical mathematical thinking, creative thinking, metacognition, development of language and literacy and development of visuo-motor coordination (Neuman, 2018; Passig, Tzuriel, \& Eshel-Kedmi,2016; Vernadakis, Avgerinos, Tsitskari, \& Zachopoulou, 2005). They can help children with learning disabilities and attention deficit disorders, children with special

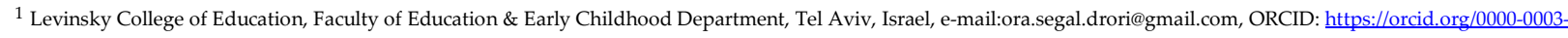
$\underline{0480-2046}$

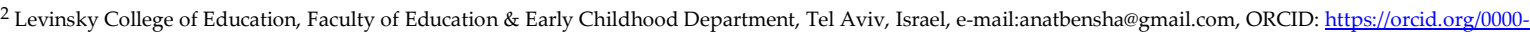
0002-9614-6092
} 
needs and children from a low socioeconomic status (Felicia, Sharif, Wong, \& Marriappan, 2014; Korat, Gitait, Bergman Deitcher, \& Mevarech, 2017). It was also found that use of digital technologies contributes to communication with friends and promotes meaningful interactions with other children, and that adult mediation for using digital technologies improves children's discourse skills (Hsin, Li, \& Chin-Chung, 2014).

Many countries encourage the use of digital technologies for preschoolers for supporting their development, and it is also recommended by the OECD (Organization for Economic Cooperation and Development) (Bakia, Murphy, Anderson, \& Trinidad, 2011). In education settings, digital technologies can be integrated for example in the area, of Information and Communications Technology (ICT). Teachers can use ICT for instruction, and for administration and communication purposes, with numerous implications for classroom management, instructional practices, pedagogical approaches and time use. Competence in using ICT and digital literacy are becoming recognized as important skills that students need to acquire if they are to flourish in the digital age (OECD, 2018).

However, in spite of the contribution of digital technology use to young children, the encouragement of countries and the OECD's recommendation to use digital technologies for preschoolers, the actual situation in many countries is far from assimilating digital technologies (Preradovićet, Lešin, \& Boras, 2017). In Israel, for example, where the present study was conducted, a national ICT program was begun in 2010, which continues to date, within whose framework schools receive budgets from the Ministry of Education to purchase digital technology means, infrastructures and maintenance, and for professional development in this field (Ministry of Education, 2017a). This program does not include preschools. The only national program that advances assimilation of digital technologies in the preschools is "Laptop for Every Preschool Teacher", which has been operating since 2012 and helps preschool teachers to acquire laptop computers and progress in their professional development (Ministry of Education, 2017b). In a model currently being developed by the Ministry of Education regarding the "Future Preschool" it is indicated that digital technologies should be integrated into the preschool pedagogy and that the children should develop technological skills in preschool, but this aspect in the model is not yet detailed (Ministry of Education, 2020). However, the actual situation in preschools in Israel is far from including digital technologies. The only recent research performed on this subject in Israel to date (Zilka, 2011) found that $10 \%$ of 150 preschools had a new computer that was connected to the internet, and the Ministry of Education policy was implemented in only $15 \%$ of the preschools. According to the Israeli Ministry of Education policy, the computer environment comprises part of the preschool's social-cultural environment and helps train an independent and active learner who uses digital technologies wisely for carrying out processes that support emotional, social and cognitive development (Ministry of Education, 2017a). Nonetheless, old computers were found in $70 \%$ of the tested preschools. However, the computer was not in use in $65 \%$ of these preschools, due to technical problems. Some preschools had one computer for 35 children (Zilka, 2011). This situation harms mainly those children who do not have access to a computer at home, and they also do not approach the computer often in the preschool. Such a situation comprises a risk for expanding digital gaps that lead to education gaps (Rogers, 2001). The preschool teachers reported difficulties in organizing the preschool, making time for each child or group of children, absence of a solution for technical problems and non-usability of the computer (Zilka, 2011).

Similar findings were reported in additional studies from Israel and elsewhere (Joshi, Pan, Murakami, \& Naranayan, 2010; Magen-Nagar and Firstater, 2017; Manessis, 2011; Ntuli and KyeiBlankson, 2010; Palaiologou, 2016b; Preradović et al., 2017). Magen-Nagar and Firstater (2017) tested the perceptions of preschool teachers in Israel regarding the assimilation of ICT in their classes. Their aim was to identify obstacles embedded in this assimilation. They found that although preschool teachers recognize the value of these media, they think that ICT does not play a major role in preschools, that ICT serves mainly as an instrument for collecting information and as an advanced teaching mean for visual illustration of the learning contents, and that ICT contributes mainly to the social interaction between the children, albeit not always in a positive manner, in particular among children with difficulties. Their main conclusion was that preschool teachers do not pose pedagogical goals that include ICT and do not realize its 
Preschoolers' views on integration of digital technologies

pedagogical potential. They use it mainly for illustration, diversification, and enrichment. The investigators indicated a need to cause preschool teachers to adopt innovative pedagogies in ways that are suitable for the preschool, with emphasis on changing the traditional perceptions.

\section{Children's Views}

Investigation of children's views or perspectives is a relatively new field of research that has developed over the past two decades. This research stemmed from the understanding that it is important to hear the children's voice and perform studies together with boys and girls, and not only about boys and girls. The aspiration was to develop research methodologies within whose framework children would not only be objects of research, but rather partners in the research (Dockett and Perry, 2003; Einarsdottir, 2010). These insights were influenced by the UN Convention on the Rights of the Child, where Section 13 states that each child will have the right to freedom of expression, including freedom to search, receive and give information and ideas of any kind, regardless of borders, orally, in writing or in print, in an artistic manner or by any other mean of their choice (United Nations, 1989). The year of the publication of the Convention on the Rights of the Child comprises a landmark that symbolizes a change in perception. Children are no longer perceived as passive objects lacking opinions and outlooks, but as subjects with opinions and independent ideas, ability to describe and interpret their routine life, power and strength, and a right to be involved in decisions that will affect them (Fargas-Malet, McSherry, Larkin, \& Robinson, 2010).

Researching children's perspectives is based on two theoretical approaches: the postmodern approach in education and the "sociology of childhood" approach. It is compatible with a democratic worldview that emphasizes the independence of all individuals in the society and their right to express their opinions. The postmodern approach perceives reality as being complex and as including many perspectives. According to this approach, there is no single objective reality and no absolute knowledge or universal truth. Knowledge is the result of social structuration and those who experience reality interpret it through their interactions with their community. Knowledge therefore exists in a specific and subjective context (Cannella, 2005). The "sociology of childhood" approach presents childhood as a unique and important period, and not only as a period of preparation for adult life. According to this approach, children are a social group that operates in a social-cultural space and maintains reciprocal relations with other groups in society, such as adults (Vandenhole, Desmet, Reynaert, \& Lembrechts, 2015). According to this perception, children are active and skilled subjects able to present attitudes and ideas (Harcourt and Conroy, 2011), to describe and interpret their routine life, have power and strength, and construct knowledge through everyday interactions with others (Alderson, 2000; Langston, Abbot, Lewis, \& Kellett, 2004).

The democratic viewpoint also comprises a point of origin for research on children's perspectives. Democracy must recognize multiple opinions and viewpoints and enable individuals to develop in different ways. In a democratic system, there is awareness of the fact that there is no one correct answer and shared meaning can be constructed through a democratic discussion. A democratic discussion is supposed to enable children to express their opinions and construct meaning for their experiences (Dahlberg, Moss, \& Pence, 2007). According to this perception, preschools should comprise a space in which diverse opinions can exist and the preschool teacher, together with the children, create a meaning that enriches thinking and participate in decision-making processes in all areas of preschool life.

The research literature in the field of investigating children's perspectives refers to construction of knowledge on children's lives from the children's point of view (Christensen and James, 2000; Clark, 2017; Corsaro and Molinari, 2000).This literature presented children's perspectives in the preschool and showed that things that are important for children can be revealed and that boys and girls are able to understand and analyze experiences in a much broader manner than we sometimes think. It is therefore important to examine and discover their views in different fields of their lives, including the field of digital technology.

Our literature review yielded very few studies on young children's views and attitudes toward integration of digital technologies in the preschool. These studies tested the knowledge, understanding and 
preferences of young children regarding the use of digital technologies in general (Aubrey and Dahl, 2014; Danovitch and Alzahabi, 2013; Dashti and Yateem, 2018; Eisen and Lillard, 2016, 2017; Palaiologou, 2016a). Other studies interviewed children on their attitudes and views regarding the use of digital technologies in the context of the school and the preschool. However, they referred solely to computers (McKenney and Voogt, 2010) or tablets (Dunn, Gray, Moffett, \& Mitchell, 2018; Oliemat, Ihmeideh, \& Alkhawaldeh, 2018). Oliemat et al. (2018) tested young children's views regarding tablets in general. They interviewed and held observations of 40 children in an educational setting, from preschool to second grade, on their use, knowledge and views in the context of tablets as well as on parents' role in supporting tablet use among children. They found that children have knowledge on tablets and their components and acquired the abilities necessary for using a tablet. However, in some cases mastery was not complete. Furthermore, children perceived tablets more as an entertainment than as a learning tool, and used them for different uses, where the most common use was playing games, followed by watching YouTube. Use of games applications and pleasure replaced traditional play activities, and the children indicated that their parents had rules regarding use of the tablet and that they need help and guidance on tablet use from their parents.

The present study explored children's views, not regarding one specific technology, but rather in general regarding digital technologies, including computers and tablets as well as smartphones, projectors, digital photography, game consoles, etc. The present study explored children's views regarding use of these technologies, but also, and especially, regarding the desired integration of these technologies in the preschool. For example, should there be such integration in the preschool, what should it include and what should be its characteristics, through in-depth interviews. Our assumption was that such research will enable better understanding of the opinions and needs of preschoolers in this context and will lead to improved and more effective integration of digital technologies in the preschool. This understanding is very important for preschool teachers in their work with children, in order to better adapt it to the needs of children in the 21st century and can contribute to optimal training of future preschool teachers in colleges of education in the context of integration of digital technologies in the preschool.

\section{Method}

\section{Participants}

The research population included 171 Israeli children, aged 3-6 (younger than 4 years: 38 [18 boys, 20 girls], $4-5$ years: 77 [38 boys, 39 girls], older than 5 years: 56 [29 boys, 27 girls]), from 37 preschools. The parents of the children gave their consent for their children's participation in the research. The children were also asked for their consent and a child who did not agree to participate, did not participate. The research procedure was approved by the ethics committees of the researchers' institute and by the Israeli Ministry of Education.

The preschools are from the national education stream, located in the center of the country. They are situated in neighborhoods with different socioeconomic statuses (SES), from the low to the high status (SES level was determined according to the Israeli Municipalities' Statistical Report, Central Bureau of Statistics, 2012).

\section{Instruments}

Semi-structured in-depth interviews were held with the children. The interviewers were undergraduate students for early childhood with experience in the researched preschools as part of their degree. They were trained by the authors on how to interview the children. Each interviewing student randomly chose four children from each preschool for interviewing (with one or two students performing interviews in each preschool). The interviews were held individually, in a quiet room in the preschool, in a one-time session that lasted 15-20 minutes. The questions which the participants were asked included: "I want to ask you about digital technologies such as a computer, tablet (iPad), smartphone, digital camera, PlayStation, Xbox, and so on. Do you use them often at home? Do you like to use them? For what?", "Do you think that the preschool should also have them? That it is important that they be in the preschool? 
Which of them should be in the preschool? Why?", "What should be done with them in the preschool? What would you like to do with them in the preschool?". The questions and the time of the interview were adapted to the child's age and/or understanding if necessary. All interviews were voice recorded and transcribed.

A single preliminary observation of the preschools was also made by the interviewing students in order to ascertain whether the preschool has digital technologies, such as computers, tablets, smartphones, television, projectors, digital photography and game consoles. These yielded a diverse situation. A few preschools had no digital technology (no computer and no television, in some there was no computer, but there was a television). Most preschools had only one computer, which was used mainly by the preschool teacher. Very few preschools had two computers. In some of the preschools where the children did use the computer, the computer was not connected to the internet and contained mainly games, including educational games, for example for learning arithmetic, literacy and language. In very few preschools the computer also included inquiry software. Five preschools had a projector. There were no tablets and no game consoles in any preschool and there was practically no use of digital cameras. A smartphone was used only by the preschool teacher.

\section{Data Analysis and Processing}

The interviews were analyzed by two coders (the authors), using content analysis. Content analysis enables identification of an organizing pattern that reflects the participants' view regarding the integration of digital technology in the preschool. The children's responses were coded through open processes. The responses were developed into categories and headings, with reference to the number of respondents who shared the same responses under each heading. Next, quotes were selected from the interviews and were used to support and develop the results.

\section{Results}

The aim of this study was to test how children perceive the integration of digital technologies in the preschool. We found that the children were aware of the existence of digital technologies in their environment, and when answering the question, what digital technologies should be added to the preschool, they indicated technologies such as television, computer, projector, tablet, computer games, game consoles such as PlayStation and Xbox, digital camera and mobile phone, which they apparently use mainly at home. In the first stage, we analyzed the in-depth interviews held with the children according to the questions they were asked. In the second stage, we identified three main categories that were raised from the children's answers: The degree to which digital technologies are necessary in the preschool; the goals of their use; and the framework for using digital technologies in the preschool. The main results are illustrated in Figure 1. 


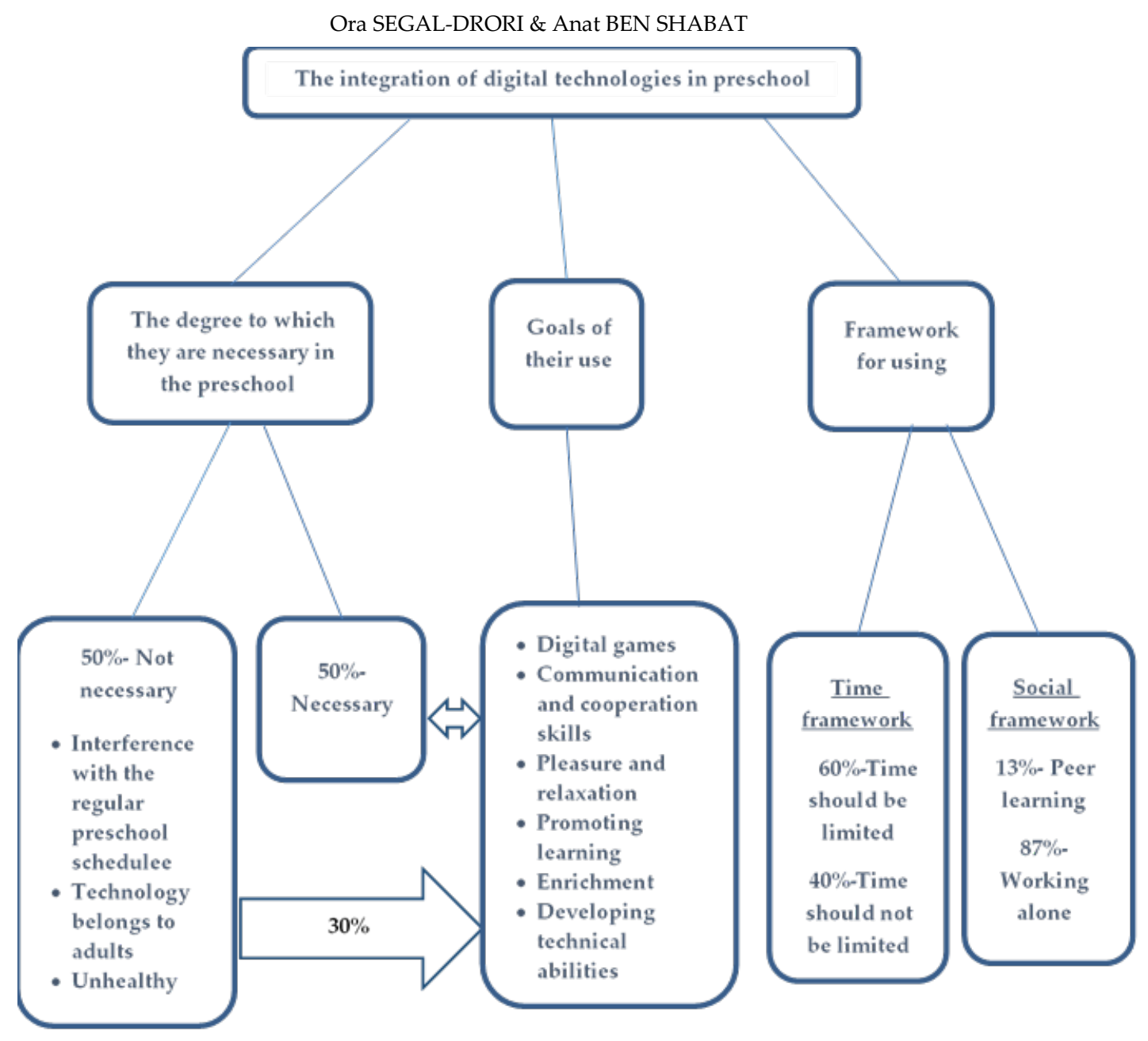

Figure 1. The participants' view regarding the integration of digital technology in the preschool

\section{The Degree to Which Digital Technologies Are Necessary in the Preschool}

Two main sub-categories arose from the children's answers regarding the degree to which digital technologies are necessary in the preschool: non-necessity of the use of digital technologies in the preschool; importance and contribution of the use of digital technologies in the preschool:

Fifty percent of the children do not perceive any need for using digital technologies in the preschool. They spoke against its integration and gave diverse reasons for this. This view is, apparently supported by examples from their life experience at home and their limited experience in preschool according to the observations which were made in their preschools. Some children perceived digital technology as a source for interferences. Some indicated that they comprise a waste of time and interference with free play, which they apparently perceive as more enjoyable or important. For example, 3.8-year-old Alma indicated that: "This is not necessary in the preschool because there are non-digital games and that is more fun". Other children indicated that this may cause interferences with the routine and distraction from the preschool teacher's explanations. Hodaya, 5.5 years old, said: "It is impossible to learn with a computer, tablet and TV, we need to listen to the teacher!". Five-year-old Ben is aware of the contribution of the other activities in the preschool: "You cannot play on the computer all day because you are wasting your time for other things". Several children claimed that digital technologies are not needed for promoting learning in the preschool, and that children learn from other sources, such as adult mediation or a book. For example, 5-year-old Yuval said: "They do not help, because learning is things that one knows from the head and from reading books, and a computer is not a real thing". Some children explained their opposition in that technology belongs solely to adults. Uri, 3.5 years old, expressed this: "Only when I am big will I play on the computer. Now I am not big". Some are afraid 
Preschoolers' views on integration of digital technologies

that the instrument will be ruined, will get lost, will not be charged (technical difficulty) or will electrocute. For example, 4.5-year-old Alex explained: "I would like to put them in a drawer so that they will not break or be destroyed". Six-year-old Lior claimed: "A person can become electrocuted by this and the charge can decrease". Hodaya, 5.5 years old, added: "It will get lost and the children will be really sad". A few children perceived their technological/technical ability as limited, and therefore it is not desirable that they use digital technologies. Four-year-old Jonathan: "This is my mom's phone. She does not allow me because I do not know". Several children said that the adults do not allow them to use digital technologies.

There were children who claimed that use of digital technologies may be dangerous and unhealthy. Some indicated that general harm to health is possible, others used arguments that describe possible injury to body parts that are more specific to use of digital technologies. It seems that some of the children heard these claims at preschool or at home, by the preschool teachers, parents or other relatives. Four-year-old Rotem: "Screens are not good for the eyes, the head and the brain". Six-year-old Hadar and 4.6-year-old Gur: "There are people who wear reading glasses because they are very close to the computer. This is not healthy for the eyes". Another argument was that these technologies emit dangerous radiation and should not be in the preschool. Omri, 5.5 years old, said: "Clearly they should not be entered into the preschool! If there will be many digital technologies, there will be more radiation, and this is harmful". Additional items that express the nonnecessity of digital technologies in the preschool explain the children's concern for unfair and unequal division of time between the children using them that may cause quarrels. Five-year-old Mor described a situation where: "In the middle everyone will want, and they will begin to cry. This will be unpleasant and unfair". Ariel, 4.5 years old, said: "Because there is only one computer and one telephone, and it will not be fair and then we can fight about this". This led to concerns about possible harm to social relations and social skills. Dor, 5.5 years old, added: "I would not like that because the friends will not play with me or with other children and will always be with the technologies". Ben, 5.5 years old, summarized: "It is more important to play with your friends".

\section{The Goals of the Use of the Digital Technologies in the Preschool}

As the interviews advanced, and reached the question: "What should be done with digital technologies in the preschool?", $30 \%$ of the children who expressed the non-necessity of the use of these technologies in the preschool added ways and goals for which they should be used in the preschool. Those children, and the other $50 \%$ of the children who thought the digital technologies are necessary in the preschool, supplied explanations on the importance and possible contribution of the use of digital technologies in the preschool. Their sayings indicate that they are well-aware of the purpose of digital technologies and understand what goals they may promote in the preschool. The children's answers present the main goal of using these technologies as games. They indicate their main occupation with digital games and their pleasure from them. Five-year-old Shai stressed the importance of introducing other digital technologies for upgrading the playing possibilities: "It is possible to play with the mobile phone in the preschool. It has games we don't have on our preschool computer".

Improving communication and cooperation skills: The children indicated the importance of shared play. Four-year-old Roy: "We are always lots of children on the computer". Some are aware of the messages transmitted by the preschool teacher and others feel the significance of shared play and express it in their own words. Four-year-old or: "From the game we have on the computer in preschool, the teacher told us that we learn to cooperate with friends". Very few stressed the experience of personal play. The children's views expressed the importance of the ability to communicate using the digital technologies, for example to "send a message", "to share what we do in preschool with the parents". The children indicated the importance of maintaining contact with the environment, in the close circle and in broader circles, in different contexts (with the family, friends, emergency responders). There were also children who indicated the possibility for peer learning. For example, 4.5-year-old Dan explained: "If someone forgets then one of the friends will explain to him and will enable him to look with the other child and see how he does it".

Twenty five percent of the children (half of those who expressed the necessity of technology) also expressed an understanding of the contribution of digital technology to promoting pleasure and relaxation. In this aspect, the children who espouse this view referred particularly to TV shows and series, YouTube 
videos and digital games. They apparently believe that an activity which uses digital technologies enables increasing relaxation, attention and concentration as a basis for other activities. Five-year-old Shaked stressed: "It is important that we play with the computer so we will calm down and only then go to the workshop". Five-year-old Ben added: "If there were no television there would be a mess, this way it is comfortable and quiet".

The children also described the way in which they perceive the integration of digital technologies as a mean for promoting diverse fields of learning. One-hundred and two children $(60 \%)$ mentioned the possible foci of learning. Zohar, 4.1 years old, and Gur, 4.6 years old, believe that technology can help to "learn and to inquire". Five-year-old Ofir reinforced this view: "The computer can help us inquire and learn because it shows lots of things". It seems that the children's answers reflected their knowledge on searching for information and the possibilities they attribute to increasing scientific knowledge by means of digital technologies. It is interesting to note that some of the children perceive the digital technologies as a mean for independent search for information and inquiry. For example, 6-year-old Dan: "If someone wants to inquire about something, then instead of the preschool teacher having to explain every second, it is possible to use the computer". Daniel, 5.5 years old, recalled: "The preschool teacher sometimes tells us to check things on the computer because perhaps there are answers to our questions". The children mentioned specific fields of knowledge which may be supported by the technology, such as learning literacy and language. Four-yearold Uri described recognition of letters and regarded the computer as a basis for learning to read and write: "I saw my name on the computer! Mother showed me how to write it". Offir, 5.5 years old, described expansion of knowledge for learning other languages: "You can learn, for example, English or Spanish, like I learn with the Mermaid, this is in English and Spanish and I try to understand what they are saying". Mathematics enrichment was also indicated. Gali, 5.5 years old, mentioned: "Sometimes you can learn numbers, arithmetic, all kinds of things like that". These quotes illustrate the children's view regarding the ability to learn arithmetic, numbers and exercises using digital technologies.

Another learning channel was identified in the children's answers, which refers to enrichment and self-instruction using digital technology. Five-year-old Itai: "On the computer, I inquired about my father because he is a pilot and I inquired about pilots". Five-year-old Emily indicated that she was exposed to new information using the tablet at home: "Yes, on the tablet I learn all kinds of things. Once I didn't know that there was a state called Hawaii, and then I heard this on the tablet".

The children indicated their technical/technological abilities that develop when using these technologies, which help their orientation with digital technologies at home, so they feel confident in using them in the preschool. The children referred to the great benefit of photographing pictures and movies, watching them and sharing with others. For example, 5.5-year-old Topaz: "It is important that there will be such instruments in the preschool so we can see movies and can learn many things from them. This is very helpful". Five-year-old Shai added: "You can photograph things from the mobile phone and send them to the iPad and then more children will see the pictures. Children can photograph each other". These answers represent the children's view that there is no limit to the knowledge they can obtain via digital technologies, via viewing pictures, listening to explanations or watching different instruction videos, which they mentioned, for example, when referring to YouTube or the teacher's computer. Other children referred to instruction that can be obtained regarding things that we can do ourselves, such as cooking, fitness or construction and creation.

\section{The Framework for Using Digital Technologies in the Preschool}

We found that the majority of the children (60\%) think that the time for using digital technologies should be limited, such as 3.8-year-old Alma, who said: "Yes, I can play on the computer just a little because it is boring". Only $40 \%$ think that play and learning with these technologies should not be limited, such as 4year-old Danielle: "We need more time on the computer during free time, this is not enough". It can be seen that the children are accustomed to having a short and limited time for using these technologies. Although time perception is not well-developed at these young ages, the children indicated recommended time periods and stressed that "we need smaller numbers" (a short time). The arguments of those who believe that there is no need to limit the time for using these technologies were that this is enjoyable and educational and should be done more and more. Others suggested not limiting the time so as not to harm the continuity of learning 
Preschoolers' views on integration of digital technologies

that is possible when using digital technologies. Five-year-old Ben: "There is no need to tell children when to stop, because maybe they are in the middle of something important, and they will be stopped in the middle and perhaps will not be able to continue to learn".

Only a small percentage referred to the social composition, which in their opinion is ascribed to the use of digital technologies in the preschool. $13 \%$ of the children expressed a preference for learning together (in a group or with friends). For example, 4.3-year-old Anael: "Yes, I would like, but together with someone else". Some of the children described an existing situation. Four-year-old Roy: "Always on the computer, we are many children". Only six children expressed a desire to play and learn alone using the digital technologies. Some perceive a computer game as something done independently, compared to non-digital games that are a social matter. Five-year-old Shai: "If the teacher would bring a tablet to the preschool, I would prefer to play on it alone, I would prefer to play regular games with friends - puzzles, cubes".

In conclusion, the findings indicate that most of the children are greatly aware of the different representations of the digital technologies that exist in their close environment, apparently mostly at home but also to a certain extent in the preschool, and recognize their importance and contribution to our lives. However, $50 \%$ (mostly the younger children, up to age 4 ) also apparently express the messages transmitted to them by the adults in their surroundings, parents, older relatives or teachers, which reflect non-necessity and danger in the context of these technologies. The non-necessity of digital technologies in the preschool was expressed in three main fields, regardless of age: these technologies may comprise interference to the regular preschool schedule, digital technology is intended solely for adults, and possible health hazards. Fifty percent of the children expressed the need to use digital technologies in the preschool and with the $30 \%$ of the children who expressed the non-necessity of the use of technologies in the preschool, indicated the goal of using these technologies and their contribution to different aspects of their lives in general, and in the preschool in particular, such as promotion of pleasure and relaxation, establishment of learning processes and enrichment in diverse learning fields.

In their answers, they also referred to the different timeframes of the activity and the social composition, which are ascribed to using digital technologies in the preschool. As to the children's view that pertains to the timeframe of using digital technologies in the preschool, it is mainly the younger children (up to age 4) who think that the time should be limited, while the older ones believe that the time for playing and learning with these technologies should not be limited. Regarding the social composition during activity with the digital technologies, the children who supported working in a group (13\%), expressed a preference for playing and learning together. Only a minority $(4 \%)$ expressed a desire to play and learn alone using these technologies. Among some of the latter, playing on the computer is perceived as something done independently, whereas non-digital games are a social matter.

\section{Conclusion and Discussion}

Three main views were raised in the present study regarding the integration of digital technologies in the preschool: the extent to which digital technologies are needed, the goals of the use of digital technologies in preschool; the setting for using digital technologies in the preschool. Fifty percent of the children, especially the younger ones, claimed that use of digital technologies is not necessary in the preschool. Their explanations referred to interference with the regular preschool schedule, the view that technology is intended for grown-ups and possible health hazards from this use. The lack of digital technologies in the preschools which these children attend, or the scarce, ineffective or unwise use of these technologies that does not arouse curiosity, may have led them to these conclusions. This importance was also indicated by the view raised in the present study, which refers to the goals of using digital technologies in the preschool. Most of the children indicated mainly or only play and pleasure. This view was also raised in their description of the use of digital technology at home. This finding is compatible with the few studies that interviewed children on their attitudes and views regarding use of digital technologies in the context of the preschool and the school (Dunn et al., 2018; McKenney and Voogt, 2010; Oliemat et al., 2018). In these studies, it was found that the children perceived these technologies as entertainment and play instruments, more than as learning tools, and that their most common activity with them was play, followed by watching 
movies, mainly on YouTube. Young children's main uses of digital technologies in the home context is also for play and pleasure. A longitudinal study conducted in the United States among 350 families found that parents gave mobile phones to their children when they had to perform house chores or to calm the children, and that most children used these technologies for pleasure and watching movies alone (Kabali et al., 2015).

The current study shows that some of the children emphasized the social aspects of digital technologies in the context of play. They expressed an understanding or desire that play with the digital technologies will be social (in a group or with friends), apparently as opposed to the individual digital games at home. The third view that was raised, that refers to the setting for using digital technologies in the preschool, indicates that several children who considered to the social aspects of digital technologies expressed a preference to play and learn together, and several children expressed a desire to play and learn alone on these technologies. Some perceive playing on the computer as something that is done independently, whereas non-digital technology games are a social matter. The preschool teacher's mediation in the context of digital technologies is therefore important in the context of shared work and social-group interactions among children, as well as with reference to the fact that young children have fewer opportunities for such contexts in the home setting. It was indeed found that use of digital technologies contributes to communication with friends and supports meaningful interactions with other children (Flewitt, Messer, \& Kucirkova, 2015; Hsin et al., 2014).

It seems that most of the children who participated in the current study understand the importance of using the digital technologies and their contribution to different aspects of their lives in general and in the preschool in particular. They indicated different aspects, such as promoting pleasure and relaxation and enrichment in different learning aspects. It seems that the children have a view of different levels of learning sources or mediation in learning, and while digital technologies are a source of learning and research in different fields, in their opinion they are not as good a source for learning and mediation as a preschool teacher or printed books. These findings emphasize the great importance and need for mediation of the preschool teacher for wise use of digital technologies in the preschool, and regarding the advantages and contribution of using these technologies for topics learned in the preschool.

These findings illustrate the importance of additional, deeper, and wiser uses of digital technologies in the preschool. The children in the present study indicated a broad range of inquiry and learning possibilities with the digital technologies in the fields of language, mathematics, scientific inquiry that includes independent inquiry ability, enrichment and instruction, making contacts with different agents, photography, watching and relaxing. Other studies also presented many and diverse examples for deep and wise uses and inquiry and learning possibilities that include digital technologies among young children (Flewitt et al., 2015; Friedman, 2018; Keren and Fridin, 2014).

Concomitantly to the above-indicated modes of mediation, it is recommended that preschool teachers explain use of these technologies to the children in an age-adapted manner. This should be accompanied by setting clear rules on wise use of these technologies and the dangers that sometimes accompany their use (for example, health hazards which the children in the present study indicated). They should also teach the children about forbidden contents and interactions with strangers (which the children in the present study did not mention), which are also very important for safe use of digital technologies. Preventing the use of digital technologies and/or frightening children regarding their use will probably not help them make wise use of these technologies. Rather, real, meaningful, relevant and greater use of these technologies by the children that will be accompanied by effective mediation of the preschool teacher is necessary. Such mediation will not only contribute to safe use of these technologies, but will also improve and increase children's understanding and learning from these technologies and will even help set the desired time setting of using the digital technologies in the preschool, which is an additional component to which the children referred in their third view. Some children think that the time for using the technologies should be limited. Others believe that the time for play and learning with these technologies should not be delineated. The preschool teacher should take the age of the children into account when determining the time of the activity with the digital technologies and his/her mediation during these activities to adapt a 
suitable time for each child with these technologies.

The present study indicates the importance of listening to children's voices on integration of digital technologies in the preschool and their perspectives and needs in this field, since they are partners to the everyday activities in the preschool. From the current study, it is possible that the children's views about digital technologies were more influenced by their home environment and less by the preschool environment, perhaps because of the limited digital technology environment which was observed in the preschools. They may also have been influenced by what they were told and or heard by adults (their parents and teachers). The children's points of view may also reflect the society and the cultural practices in Israel regarding the use of digital technologies. There is very limited literature on these aspects among parents to young children (Elias and Sulkin, 2017, 2019; Lev and Elias, 2020) and preschool teachers (Magen-Nagar and Firstater, 2017; Zilka, 2011) in Israel. Magen-Nagar and Firstater (2017) for example, found that preschool teachers do indeed recognize the value of the digital technologies. However, in their opinion such technologies do not play a major role in preschools and are mainly used as instruments for collecting information and as a teaching mean for visual illustration of the learning contents. These means contribute mainly to the social interaction between the children, albeit not always in a positive manner especially among children with difficulties. Their main conclusion was that preschool teachers generally do not formulate pedagogical goals that include digital technologies and thus do not realize their pedagogical potential. The teachers use digital technologies mostly for illustration, diversification and enrichment. Elias and Sulkin $(2017,2019)$ and Lev and Elias (2020) who investigated the use of digital technologies at home among toddlers until age 3 revealed that using digital technologies has become normative behavior among toddlers. This emphasizes how deeply use of digital technologies is integrated into the basic daily routine of parents to very young children who use digital technologies platforms to fulfill a wide range of their childrearing needs. Their use of digital technologies is mainly instrumental, as a babysitter, for schedule regulation, family time and before bedtime and not for children's enrichment. In addition, the children were exposed to contents not intended for them and experienced limited interaction with their parents during this activity.

It is therefore recommended that future research investigate the perspectives of preschoolers in this context at greater depth in an attempt to understand the sources for the children's views and their influences. This may be achieved by using additional means beyond personal depth interviews, such as group discussions on this issue, asking the children to draw or photograph the things that are important to them in this field and talking with them about it, videotaping children during interactions that include digital technologies in individual and group settings and with the preschool teacher's mediation, and afterwards watching them together and interviewing the children in order to understand their interpretation of the videotaped interactions. After collecting these data, the preschool teachers can integrate and mediate digital technologies more intelligently, in a way that is adapted to the children's understanding and view of these technologies. The children in the current study referred to the integration of the digital technologies, to the promotion of pleasure and relaxation, establishment of learning processes and enrichment in diverse learning field, as well as to time frames of activities with these technologies and their social composition.

To complete the overall picture, it is also advisable to examine the perspectives of preschoolers in this context in greater depth and using quantitative research methods, with reference to the children's SES. It is recommended to examine the views of preschool teachers and parents on the integration of digital technologies in preschool. İt is further recommended to compare these issues to countries and cultures other than Israel.

According to the limited digital technology environment in the preschools which was observed and raised from the children's descriptions in the current study, as well as from the very few studies which were performed in Israel (Magen-Nagar and Firstater, 2017; Zilka, 2011), it is possible that the preschool teachers in Israel may be encouraged to increase their integration and mediation of digital technologies and to do so in a more developmentally appropriate practice. The Ministry of Education is currently developing a model of the "Future Preschool", where it stresses the need to integrate digital technologies into preschool 
pedagogy. The model claims that children should be supported in the development of technological skills in preschool. However, this part of the model has not been completed, and has not been formulated in detail as yet (Ministry of Education, 2020). There might be a stronger and clearer Ministry of Education policy in this field, as recommended by the global policy (see, for example, the recommendations of the OECD and the National Association for the Education of Young Children (NAEYC) as presented in Bakia et al., 2011 and Radich, 2013). This situation may have a greater influence on preschoolers' views about optimal integration of digital technologies in the preschool in general, and on more positive views in this aspect, especially among the younger preschoolers as emerged from the present study. Preschool teachers might integrate and mediate digital technologies more wisely, and in a manner adapted to the children's understanding and view toward these technologies. Such integration will enable 21st century preschoolers to better adapt their needs and the needs of society in the present and in the future and prevent a risk for expanding digital gaps that lead to education gaps.

\section{Declarations}

Authors' contributions: The all study and manuscript: Both the authors.

Competing interests: The authors declare that they have no competing interests.

Funding: Not applicable.

\section{References}

Alderson, P. (2000). Children as researchers: The effects of participation rights on research methodology. In P. Christensen \& A. James (Eds.) Research with children: Perspectives and practices (pp. 241-257). London: Falmer.

Aubrey, C., \& Dahl, S. (2014). The confidence and competence in information and communication technologies of practitioners, parents and young children in the Early Years Foundation Stage. Early Years: An International Research Journal, 34(1), 94-108. https://doi.org/10.1080/09575146.2013.792789

Bakia, M., Murphy, R., Anderson, K., \& Trinidad, G. E. (2011). International experiences with technology in education. U.S. Department of Education, Office of Educational Technology and the Office of Planning, Evaluation and Policy Development, Policy and Program Studies Service.

Brown, A. (2011). Media use by children younger than 2 years. Pediatrics, 128(5), 1040-1045. https://doi.org/10.1542/peds.2011-1753

Cannella, G. S. (2005). Reconceptualizing the field (of early care and education): If 'western' child development is a problem, then what do we do? In N. Yelland (Ed.) Critical issues in early childhood education (pp. 17-39). Maidenhead, UK: Open University Press.

Central Bureau of Statistics. (2012). Shnaton statisiti leisrael .[Israel demographic profile].

Chassiakos, Y. L. R., Radesky, J., Christakis, D., Moreno, M. A., \& Cross, C. (2016). Children and adolescents and digital media. Pediatrics, 138(5), e20162593. https://doi.org/10.1542/peds.2016-2593

Christensen, P. \& James, A. (2000). Researching children and childhood: Cultures of communication. In P. Christensen, \& A. James (Eds.) Research with children: Perspectives and practices (pp. 1-8). London: Falmer. https://doi.org/10.1177/0907568200007004003

Clark, A. (2017). Listening to young children, expanded third edition: A guide to understanding and using the mosaic approach. London: Jessica Kingsley Publishers.

Corsaro, W. A., \& Molinari, L. (2000). Entering and observing in children's worlds: A reflection on a longitudinal ethnography of early education in Italy. In P. Christensen, \& A. James (Eds.) Research with children: Perspectives and practices (pp. 179-200). London: Falmer.

Dahlberg, G., Moss, P., \& Pence, A. (2007). Beyond quality in early childhood education and care: Languages of evaluation (2nd ed.). Abingdon, UK and New York: Routledge. https://doi.org/10.4324/9780203966150

Danovitch, J. H., \& Alzahabi, R. (2013). Children show selective trust in technological informants. Journal of Cognition and Development, 14(3), 499-513. https://doi.org/10.1080/15248372.2012.689391

Dashti, F., \& Yateem, A. (2018). Use of mobile devices: A case study with children from Kuwait and the United States. International $\begin{array}{llll}\text { Journal of } & \text { Early } & \text { Childhood, } & \text { 50(1), }\end{array}$ https://doi.org/10.1007/s13158-018-0208-x

Dockett, S., \& Perry, B. (2003). Children's views and children's voices in starting school. Australian Journal of Early Childhood, 28(1), 1217. https://doi.org/10.1177/183693910302800104

Dunn, J., Gray, C., Moffett, P., \& Mitchell, D. (2018). 'It's more funner than doing work': Children's perspectives on using tablet 
Preschoolers' views on integration of digital technologies

computers in the early years of school. Early Child Development and Care, 188(6), 819-831. https://doi.org/10.1080/03004430.2016.1238824

Ebbeck, M., Yim, H. Y. B., Chan, Y., \& Goh, M. (2016). Singaporean parents' views of their young children's access and use of technological devices. Early Childhood Education Journal, 44(2), 127-134. https://doi.org/10.1007/s10643-015-0695-4

Einarsdottir, J. (2010). Children's experiences of the first year of primary school. European Early Childhood Education Research Journal, 18(2), 163-180. https://doi.org/10.1080/13502931003784370

Eisen, S., \& Lillard, A. S. (2016). Just Google it: Young children's preferences for touchscreens versus books in hypothetical learning tasks. Frontiers in Psychology, 7, 1431. https://doi.org/10.3389/fpsyg.2016.01431

Eisen, S., \& Lillard, A. S. (2017). Young children's thinking about touchscreens versus other media in the US. Journal of Children and Media, 11(2), 167-179. https://doi.org/10.1080/17482798.2016.1254095

Elias, N., \& Sulkin, I. (2017). YouTube viewers in diapers: An exploration of factors associated with amount of toddlers' online viewing. Cyberpsychology: Journal of Psychosocial Research on Cyberspace, 11(3), article 2. https://doi.org/10.5817/CP2017-3-2

Elias, N., \& Sulkin, I. (2019). Screen-assisted parenting: The relationship between toddlers' screen time and parents' use of media as a parenting tool. Journal of Family Issues, 40(18), 2801-2822. https://doi.org/10.1177/0192513X19864983

Fargas-Malet, M., McSherry, D., Larkin, E., \& Robinson, C. (2010). Research with children: Methodological issues and innovative techniques. Journal of Early Childhood Research, 8(2), 175-192. https://doi.org/10.1177/1476718X09345412

Felicia, A., Sharif, S., Wong, W., \& Marriappan, M. (2014). Innovation of assistive technologies in special education: A review. Journal of Enhanced Research in Educational Development, 2(3), 25-38.

Flewitt, R., Messer, D., \& Kucirkova, N. (2015). New directions for early literacy in a digital Age: The iPad. Journal of Early Childhood Literacy, 15(3), 289-310. https://doi.org/10.1177/1468798414533560

Friedman, A. (2018). To "Read" and "Write" pictures in early childhood: Multimodal visual literacy through Israeli children's digital photography. Journal of Children and Media, 12(3), 312-328. https://doi.org/10.1080/17482798.2018.1443147

Harcourt, D., \& Conroy, C. (2011). Informed consent. In D. Harcourt, B. Perry, \& T. Waller (Eds.) Researching young children's perspectives (pp. 38-51). London: Routledge.

Holloway, D., Green, L., \& Livingstone, S. (2013). Zero to eight: Young children and their internet use. London: EU Kids Online.

Hsin, C. T., Li, M. C., \& Chin-Chung, T. (2014). The influence of young children's use of technology on their learning: A review. Journal of Educational Technology and Society, 17(4), 85-99.

Joshi, A., Pan, A., Murakami, M., \& Naranayan, S. (2010). Role of computers in educating young children: U.S. and Japanese teachers' $\begin{array}{lllll}\text { perspectives. Computers } & \text { Schools, } & \text { 27(1), } & \text { 5-19. }\end{array}$ https://doi.org/10.1080/07380560903536249

Kabali, H. K., Irigoyen, M. M., Nunez-Davis, R., Budacki, J. G., Mohanty, S. H., Leister, K. P., \& Bonner, R. L. (2015). Exposure and use of mobile media devices by young children. Pediatrics, 136(6), 1044-1050. https://doi.org/10.1542/peds.2015-2151

Keren, G., \& Fridin, M. (2014). Kindergarten Social Assistive Robot (KindSAR) for children's geometric thinking and metacognitive development in preschool education: A pilot study. Computers in Human Behavior, 35, 400-412. https://doi.org/10.1016/j.chb.2014.03.009

Korat, O., Gitait, A., Bergman Deitcher, D., \& Mevarech, Z. (2017). Early literacy programme as support for immigrant children and as transfer to early numeracy. Early Child Development and Care, 187(3-4), $672-689$. https://doi.org/10.1080/03004430.2016.1273221

Langston, A., Abbot, L., Lewis, V., \& Kellett, M. (2004). Early childhood. In S. Fraser, V. Lewis, S. Ding, M. Kellett, \& C. Robinson (Eds.), Doing research with children and young people (pp.147-160). Thousand Oaks, CA: Sage.

Lev, Y. B., \& Elias, N. (2020). Digital Parenting: Media uses in parenting routines during the first two years of life. Studies in Media and Communication, 8(2), 41-48. https://doi.org/10.11114/smc.v8i2.5050

Magen-Nagar, N., \& Firstater, E. (2017). Michsholim behatmahat hatikshuv began hayeladim- tfisot shel gananot [Obstacles in the assimilation of ICT in the preschool- preschool teachers' perceptions]. Hokrim Hagil Harach, 6, 62-94.

Manessis, D. (2011). Early childhood post-educated teachers' views and intentions about using digital games in the classroom. Proceedings of the $5^{\text {th }}$ European Conference on Games Based Learning, 753-758.

McKenney, S., \& Voogt, J. (2010). Technology and young children: How 4-7 year olds perceive their own use of computers. Computers in Human Behavior, 26(4), 656-664. https://doi.org/10.1016/j.chb.2010.01.002

Ministry of Education. (2017a). Hahanan hachinuchi-Kol hasherutim hametukshavim lebatei hasefer: Tochnit hatikshuv. [The educational cloud - all ICT services for the schools: The ICT program]. Retrieved September 1, 2020, from http://sites.education.gov.il/cloud/home/tikshuv/Pages/tikshuv.aspx. 


\section{Ora SEGAL-DRORI \& Anat BEN SHABAT}

Ministry of Education. (2017b). Hahanan hachinuchi- Kol hasherutim hametukshavim lebatei hasefer: Machev nayad lecol more- Keren Atena [The educational cloud-all ICT services for the schools: A laptop computer for every teacher - Atana Fund]. Retrieved September 1, 2020, from http://sites.education.gov.il/cloud/home/tikshuv/Pages/machshev_nayad_atana.aspx.

Ministry of Education. (2020). Model hagan hahatidi [The future preschool model]. Retrieved December 17, 2020, from https://edu.gov.il/minhalpedagogy/preschool/subjects/Pages/ganatidi.aspx.

Neumann, M. M. (2018). Using tablets and apps to enhance emergent literacy skills in young children. Early Childhood Research Quarterly, 42(1), 239-246. https://doi.org/10.1016/j.ecresq.2017.10.006

$\mathrm{Ng}$, W. (2016). New digital technology in education. Switzerland: Springer International Publishing. https://doi.org/10.1007/978-3-319-05822-1 5

Ntuli, E., \& Kyei-Blankson, L. (2010). Teachers' understanding and use of developmentally appropriate computer technology in early childhood education. Journal of Technology Integration in the Classroom, 2(3), 23-35.

OECD. (2018). PISA 2021 ICT framework. Retrieved December 14, 2020, from https://pdfs.semanticscholar.org/2cb3/917fc189d08018d295dfebec8a68cbbc8d88.pdf

Oliemat, E., Ihmeideh, F., \& Alkhawaldeh, M. (2018). The use of touch-screen tablets in early childhood: Children's knowledge, skills, and attitudes towards tablet technology. Children and Youth Services Review, 88, 591-597. https://doi.org/10.1016/j.childyouth.2018.03.028

Palaiologou, I. (2016a). Children under five and digital technologies: Implications for early years pedagogy. European Early Childhood Education Research Journal, 24(1), 5-24. https://doi.org/10.1080/1350293X.2014.929876

Palaiologou, I. (2016b). Teachers' dispositions towards the role of digital devices in play-based pedagogy in early childhood education. Early Years, 36(3), 305-321. https://doi.org/10.1080/09575146.2016.1174816

Passig, D., Tzuriel, D., \& Eshel-Kedmi, G. (2016). Improving children's cognitive modifiability by dynamic assessment in 3D Immersive Virtual Reality environments. Computers and Education, 95, 296-308. https://doi.org/10.1016/j.compedu.2016.01.009

Preradović, N. M., Lešin, G., \& Boras, D. (2017). The role and attitudes of kindergarten educators in ICT-supported early childhood education. Tem Journal, 6(1), 162-172.

Radich, J. (2013). Technology and interactive media as tools in early childhood programs serving children from birth through age 8. Every Child, 19(4), 18-19.

Rogers, E. M. (2001). The digital divide. Convergence, $7(4), \quad 96-111$. https://doi.org/10.1177/135485650100700406

United Nations. (1989). The United Nations Convention on the Rights of the Child [UNCRC]. New York: UNICEF.

Vandenhole, W., Desmet, E., Reynaert, D., \& Lembrechts, S. (Eds.). (2015). Routledge international handbook of children's rights studies. New York: Routledge. https://doi.org/10.4324/9781315769530

Vernadakis, N., Avgerinos, A., Tsitskari, E., \& Zachopoulou, E. (2005). The use of computer assisted instruction in preschool education: Making teaching meaningful. Early Childhood Education Journal, 33(2), 99-104. https://doi.org/10.1007/s10643-005$\underline{0026-2}$

Zilka, G. (2011). Sviva limudit digitalit beganei hayeladim [Digital environment in the kindergartens]. In D. Chen, \& G. Kurtz (Eds.), Tikshuv lemida vehoraha [ICT, learning and teaching] (pp. 207-230). Or-Yehuda: The Center for Academic Studies. 